\title{
PENGARUH MODEL PEMBELAJARAN INKUIRI TERHADAP PEMAHAMAN KONSEP IPA SISWA KELAS V SDN PERESAK BEBUAK KECAMATAN KOPANG TAHUN AJARAN 2020/2021
}

\author{
Arif Rahman Hakim ${ }^{1)}$, M. Liwa Ilhamdi2), Abdul Kadir Jaelani ${ }^{3)}$ \\ 1,2,3) Program Studi PGSD, FKIP - Universitas Mataram \\ *Corresponding Author: arifarmypgsd@gmail.com
}

\begin{tabular}{|c|c|}
\hline ARTICLE INFO & ABSTRACT \\
\hline $\begin{array}{l}\text { Article history } \\
\text { Received: October } 8^{\text {st }}, 2020 \\
\text { Revised : November } 9^{\text {st }}, 2020 \\
\text { Accepted : November } 21^{\text {st }}, 2020 \\
\text { Keywords: } \\
\text { Inquiry Learning Model, } \\
\text { Understanding the Concept of } \\
\text { Science }\end{array}$ & $\begin{array}{l}\text { Penelitian ini bertujuan untuk mengetahui ada atau tidaknya } \\
\text { pengaruh model pembelajaran inkuiri terhadap pemahaman konsep } \\
\text { IPA siswa kelas V SDN Peresak Bebuak Kecamatan Kopang Tahun } \\
\text { Aajaran 2020/2021. Penelitian ini menggunakan pendekatan } \\
\text { kuantitatif dengan metode Pre- Experimental Design type one group } \\
\text { pretest- posttet Design. Populasi dalam penelitian ini adalah siswa } \\
\text { kelas V SD dengan jumlah } 35 \text { siswa. Teknik pengambilan sampel } \\
\text { menggunakan Nonprobability Sampling dengan jumlah sampel } 35 \\
\text { siswa. Teknik pengumpulan data dalam penelitian ini menggunakan } \\
\text { soal tes uraian dan lembar observasi. Teknik analisis data yang } \\
\text { digunakan adalah uji t dengan jenis paired sample t-test. Hasil } \\
\text { pengujian hipotesis menunjukkan nilai sig. (2-tailed) pemahaman } \\
\text { konsep IPA siswa bernilai sama yaitu 0,000 pada taraf signifikansi } \\
5 \% \text { dengan jumlah N=35. Nilai sig.(2-tailed) tersebut menunjukkan } \\
\text { bahwa ada pengaruh yang signifikan model Pembelajaran Inkuiri } \\
\text { terhadap pemahaman konsep IPA siswa kelas IV di SDN Peresak } \\
\text { Bebuak Tahun Ajaran 2020/2021. }\end{array}$ \\
\hline
\end{tabular}

\section{A. Pendahuluan}

Pembelajaran di sekolah dasar mempunyai tujuan agar memberikan pengetahuan dasar dan konsep kepada siswa tentang berbagai ilmu yang terdapat dalam materi pelajaran. Salah satunya adalah IPA yang merupakan pembelajaran di sekolah dasar yanag membantu siswa dalam menyelesaikan masalah dalam kehidupan sehari-hari sehingga siswa dapat berpikir secara ilmiah. Ilmu Pengetahuan Alam merupakan cara mencari tahu tentang alam sekitar secara sistematis (Sochibin, 2009:96).

Siswa juga diharapkan dapat memahami konsep-konsep pada materi IPA. Guru harus menyadari bahwa Belajar merupakan perubahan tingkah laku dalam diri seseorang sebagai dampak dari pengalaman yang didapatkan dengan penuh kesadaran. Tolak ukur keberhasilan proses belajar mengajar diukur dari banyaknya pengalaman belajar yang dicapai siswa (Handayani, dkk. 2020:78). Perubahan tingkah laku tersebut dapat berupa perubahan keterampilan, kebiasaan, sikap, pengetahuan, pemahaman, dan apresiasi. Hal ini membutuhkan kemampuan professional guru dalam melaksanakan pembelajaran yaitu guru harus mampu menyediakan pengalaman belajar yang memperhatikan modus pengalaman belajar, yaitu $10 \%$ dari apa yang kita baca, $20 \%$ dari apa yang kita dengar, $30 \%$ dari apa yang kita lihat, $50 \%$ dari apa yang kita lihat dan dengar, $70 \%$ dari apa yang kita katakan, dan $90 \%$ dari apa yang kita katakan dan lakukan (Deporter dalam Akbar, 2017:48). Ini menunjukkan bahwa jika guru 
mengajar dengan ceramah maka siswa akan mengingat dan menguasai hanya $20 \%$ karena siswa hanya mendengarkan. Namun, jika guru meminta siswa untuk melakukan sesuatu dan melaporkannya maka siswa akan mengingat dan menguasai materi yang diajarkan sebanyak $90 \%$.

Berdasarkan hasil pengamatan yang dilakukan oleh penulis di kelas V SDN Peresak Bebuak, pada saat pembelajaran IPA ternyata guru dalam mengajar belum melibatkan siswa secara aktif dalam proses pembelajaran. Metode yang dikembangkan cenderung ceramah, guru menjelaskan kemudian siswa mendengarkan penjelasan guru. Guru belum menggunakan media dalam pembelajaran. Pada awal pembelajaran guru tidak melakukan apersepsi, guru kurang membangkitkan motivasi terhadap pembelajaran, siswa tidak memperhatikan penjelasan guru, dalam menyampaikan materi kurang menarik sehingga pembelajaran terasa membosankan dan dalam pembelajaran juga guru tidak melakukan percobaan untuk menjelaskan konsep-konsep IPA. Hal ini menyebabkan siswa belum mengalami kebermaknaan proses pembelajaran.

Masalah pembelajaran di atas memerlukan pemecahan. Salah satu alternatif pemecahannya yaitu dengan menerapkan model pembelajaran yang tidak mengharuskan siswa menghafal fakta-fakta, tetapi model yang dapat membuat pembelajaran lebih bermakna. Siswa perlu mengerti makna belajar beserta manfaatnya sehingga mereka bisa menempatkan diri sebagai manusia yang memerlukan suatu bekal untuk hidupnya. Mereka mempelajari apa yang bermanfaat bagi dirinya dan berupaya menggapainya dengan guru sebagai pengarah dan pembimbing. Oleh karena itu, diperlukan suatu model pembelajaran yang tepat yaitu pembelajaran inkuiri.

Berdasarkan latar belakang tersebut maka penelitian dengan judul "Pengaruh Model Pembelajaran Inkuiri Terhadap Pemahaman Konsep Siswa di SDN Peresak Bebuak Tahun Ajaran 2020/2021" perlu dilakukan.

\section{B. METODE PENELITIAN}

Jenis penelitian yang digunakan dalam penelitian ini adalah penelitian eksperimen. Penelitian eksperimen dapat diartikan sebagai metode penelitian yang digunakan untuk mencari pengaruh perlakukan tertentu terhadap yang lain dalam kondisi yang terkendalikan (Sugiyono 2018: 72). Jenis penelitian eksperimen yang digunakan adalah Pre-Experimental Design tipe one group pretest-posttet Design. Penelitian ini dilakukan terhadap satu kelompok kelas eksperimen yang tidak dipilih secara random. Adapun subjek dalam penelitian ini adalah seluruh siswa kelas V di SDN Peresak Bebuak dengan jumlah 35 siswa.

Teknik pengumpulan data yang digunakan dalam penelitian ini adalah tes dan observasi. Dalam penelitian ini, tes digunakan untuk mengetahui tingkat pencapaian pemahaman konsep IPA di kelas V di SDN Peresak Bebuak dengan menggunakan model Pembelajaran Inkuiri. Bentuk tes yang digunakan dalam penelitian ini adalah berupa tes uraian dengan jumlah 5 soal untuk memperole data-data hasil pretest dan postest siswa pada muatan IPA. Adapun lembar obseervasi digunakan untuk mengetahui keterlaksanaan model pembelajaran inkuiri.

Teknik analisis data yang digunakan dalam penelitian yaitu uji paired sample t- test dengan bantuan SPSS versi 16. Namun, sebelum melakukan uji hipotesis maka dilakukan uji prasyarat yaitu uji normalitas dan uji homogenitas untuk mengetahui apakah data berdistribusi normal dan homogen atau tidak. Jika data berdistribusi normal dan homogen maka uji parametric menggunakan uji paired sample t-test dapat dilakukan. Adapun cara yang digunakan dalam pengambilan keputusan dengan uji hipotesis paired sample t-test menggunakan SPSS yaitu apabila nilai Sig. (2-tailed) $\leq 0.05$ maka 
$\mathrm{H}_{\mathrm{a}}$ diterima dan $\mathrm{H}_{0}$ ditolak, sedangkan jika nilai Sig. (2-tailed) $\geq 0.05$ maka $\mathrm{H}_{0}$ diterima dan $\mathrm{H}_{\mathrm{a}}$ ditolak.

\section{HASIL DAN PEMBAHASAN}

Penelitian dengan judul pengaruh model pembelajaran inkuiri terhadap pemahaman konsep IPA siswa kelas V SDN Peresak Bebuak kecamatan Kopang Tahun Ajaran 2020/2021 menggunakan instrument tes dalam bentuk uraian dengan jumlah 5 soal yang telah melalui uji expert memperoleh data hasil penelitian sebagai berikut :

Tabel 1. Data Hasil Pretest dan Postest Kelas Eksperimen

\begin{tabular}{|c|c|c|}
\hline Aspek & Pretest & Postest \\
\hline Nilai Tertinggi & 60 & 95 \\
\hline Nilai Terendah & 30 & 65 \\
\hline Nilai Rata - Rata & 48,61 & 83,33 \\
\hline
\end{tabular}

Dari data nilai rata-rata pre-test dan post-test pemahaman konsep IPA kelas V SDN Peresak Bebuak di atas, terlihat bahwa nilai rata-rata siswa pada tes awal (pre-test) adalah 48,61 dengan nilai tinggi 60 dan nilai terendah 30. Selanjutnya nilai rata-rata yang dihasilkan pada tes akhir (post-test) adalah 83,33 dengan nilai tertinggi 95 dan nilai terendah 65. Berdasarkan dari hasil analisis data di atas, diketahui bahwa hasil pemahaman konsep siswa kelas V di SDN Peresak Bebuak setelah diberikannya perlakuan (postest) lebih baik jika dibandingkan dengan hasil belajar yang diperoleh sebelum diberikan perlakuan (pretest).

Setelah data hasil belajar siswa kelas V SDN Peresak Bebuak tahun ajaran 2020/2021 diperoleh, maka langkah selanjutnya yaitu dengan melakukan uji prasyarat yaitu uji normalitas dan uji homogenitas, sebelum melakukan uji hipotesis menggunakan paired sample t-test. Uji normalitas data dalam penelitian ini menggunakan uji normalitas Kolmogorov-Smirnov dengan bantuan aplikasi SPSS Versi 16 dengan taraf signifikansi $5 \%$ atau 0,05 pada data pretes maupun postest siswa di kelas eksperimen. Jadi data dikatakan berdistribusi normal jika nilai signifikansi lebih besar dari 0,05.

Tabel 2. Tests of Normality

\begin{tabular}{|l|r|r|r|r|r|r|}
\hline & \multicolumn{3}{|c|}{ Kolmogorov-Smirnov ${ }^{\mathrm{a}}$} & \multicolumn{3}{|c|}{ Shapiro-Wilk } \\
\cline { 2 - 7 } & Statistic & \multicolumn{1}{c|}{$\mathrm{df}$} & \multicolumn{1}{c|}{ Sig. } & Statistic & \multicolumn{1}{c|}{$\mathrm{df}$} & \multicolumn{1}{c|}{ Sig. } \\
\hline Pretest_Eksperim & .201 & 17 & .068 & .930 & 17 & .220 \\
en & .202 & 17 & .063 & .929 & 17 & .206 \\
Pretest_Kontrol & .166 & 17 & $.200^{*}$ & .921 & 17 & .155 \\
Posttest_Eksperi & & & & & & \\
men & .093 & 17 & $.200^{*}$ & .985 & 17 & .989 \\
\hline
\end{tabular}

a. Lilliefors Significance Correction

*. This is a lower bound of the true significance.

Adapun hasil dari uji normalitas dalam penelitian ini yaitu sebesar 0,068 $>0,05$ yang dapat disimpulkan bahwa nilai pretets kelas eksperimen berdistribusi normal. 
Selanjutnya nilai postest hasil penyelesaian soal pemahamn konsep IPA kelas V di SDN Peresak Bebuak sebesar 0,200 $>0,05$ yang dapat disimpulkan bahwa nilai postest berdistribusi normal.

Uji homogenitas bertujuan untuk mengetahui apakah objek yang diteliti mempunyai varian homogen atau tidak. Uji homogenitas varians terbesar dan varians terkecil dengan menggunakan selisih nilai post-test dan pre-test kedua kelas digunakan untuk mengetahui tindak lanjut uji hipotesis (t-test) yang akan digunakan, berikut hasil uji homogenitas menggunakan uji Levene Statistic dengan bantuan aplikasi SPSS 16.0 for windows yang disajikan dalam bentuk tabel.

\section{Tabel 3. Uji Homogenitas Kelas Eksperimen dan Kontrol}

\begin{tabular}{|c|c|c|c|c|}
\hline & Levene Statistic & df1 & $\mathrm{df2}$ & Sig. \\
\hline Nilai_Pretest & 2.293 & 1 & 33 & .139 \\
\hline Nilai_Posttest & 1.882 & 1 & 33 & .179 \\
\hline
\end{tabular}

Berdasarkan tabel diatas nilai signifikansi (sig) pada pre-test adalah sebesar 0,139 dan post-test sebesar $0,179>0,05$, sehingga dapat disimpulkan bahwa varian data untuk pre-test dan post-test adalah sama atau varian sampel penelitian ini homogen. Setelah melalui uji persyarat dengan uji normalitas dan homogenitas, maka dapat digunakan uji hipotesis. Adapun uji hipotesis dalam penelitian ini mengunakan uji-t dua pihak, yaitu menggunakan rumus t-test dengan polled varian dengan kriteria pengujian yaitu jika $t_{\text {hitung }}>\mathrm{t}_{\text {tabel }}$ maka Ho ditolak dan Ha diterima atau Jika $t_{\text {hitung }}<t_{\text {tabel }}$, maka Ho diterima dan Ha ditolak pada taraf signifikansi 5\%.Hasil uji-t dari posttest pemahaman konsep IPA dapat dilihat $t_{\text {hitung }}>t_{\text {tabel }}$ yaitu $9,262>2,035$ pada taraf signifikan $5 \%$ dengan derajat kebebasan $(\mathrm{df})=17+18-2=33$ Sesuai dengan kriteria pengujian hipotesis yaitu $t_{\text {hitung }}>t_{\text {tabel, }}$ maka Ha diterima dan Ho ditolak. Hal ini menunjukkan bahwa ada pengaruh yang signifikan penggunaan model pembelajaran inkuiri terhadap pemahaman konsep IPA siswa kelas V di SDN Peresak Bebuak tahun ajaran 2020/2021.

\section{Tabel Kriteria Uji Reliabilitas Instrumen}

\begin{tabular}{cc}
\hline Koefisien Korelasi & Kriteria \\
\hline $0,80 \leq \mathrm{r} \leq 1,00$ & Sangat Tinggi \\
$0,60 \leq \mathrm{r} \leq 0,80$ & Tinggi \\
$0,40 \leq \mathrm{r} \leq 0,60$ & Cukup \\
$0,20 \leq \mathrm{r} \leq 0,40$ & Rendah \\
$-1,00 \leq \mathrm{r} \leq 0,20$ & Sangat Rendah \\
\hline
\end{tabular}

Adapun uji gain Dari hasil perhitungan nilai effect size (ES) diatas di dapatkan hasil sebesar 3,74 dilihat dari kriteria berada pada kisaran nilai $>0,80$ sehingga model pembelajaran inkuiri berpngaruh sangat tinggi terhadap pemahaman konsep IPA siswa.

Hal ini sejalan dengan menurut Khair (2018:100) pembelajaran inkuiri memberikan peluang dan kesempatan yang lebih besar bagi siswa untuk mempelajari cara menemukan fakta, konsep, dan prinsip melalui pengalamannya sendiri secara langsung. bertalian dengan itu. Jadi kegiatan belajar yang dilakukan dengan menggunakan metode resource based learning ini dalam menyampaikan bahan 
pelajaran kepada siswa dengan menggunakan berbagai sumber belajar yang dapat meningkatkan pengetahuan dan keaktifan siswa dalam memperoleh informasi, aktif dalam berdiskusi dengan teman kelompok untuk mencari materi dan menyelesaikan masalah, aktif dalam bertanya kepada guru ataupun temannya, kemudian bekerjasama dengan baik bersama teman kelompoknya dalam menyelesaikan latihan-latihan soal yang diberikan oleh guru.

Hal ini senada dengan penelitian yang dilakukan oleh Rofiqoh, tentang "Pengaruh Pendekatan Inkuiri Terhadap Hasil Belajar Peserta Didik Dalam Mata Pelajaran IPA Kelas IV SD Negeri Mannuruki”. Hasil belajar peserta didik yang diajar dengan penerapan pendekatan inkuiri kelas IV, memiliki presentase sebesar 33,33\% pada kategori sangat tinggi $66,66 \%$ berada pada kategori tinggi dimana kriteria pengujian terima $\mathrm{H}_{1}$ jika $\mathrm{t}_{\text {hitung }}=8.19>\mathrm{t}_{\text {tabel }} 2,045$, hal ini dapat ditarik kesimpulan bahwa pengaruh pendekatan inkuiri terhadap hasil belajar peserta didik dalam mata pelajaran IPA kelas IV SD Negeri Mannuruku.

\section{PENUTUP}

\section{Simpulan}

Berdasarkan hasil analisis data yang telah dipaparkan di atas dapat disimpulkan bahwa terdapat pengaruh yang signifikan penggunaan model pembelajaran inkuiri terhadap pemahaman konsep IPA siswa kelas V di SDN Peresak Bebuak tahun ajaran 2020/2021. Hal ini ditunjukkan dengan Nilai rata-rata siswa pada tes awal (pretest) adalah 48,61 dengan nilai tinggi 60 dan nilai terendah 30. Sedangkan nilai rata- rata yang dihasilkan pada tes akhir (postest) adalah 83,33 dengan nilai tertinggi 95 dan nilai terendah 65. Adapun uji hipotesis dalam penelitian ini mengunakan uji-t dua pihak, yaitu menggunakan rumus t-test dengan polled varian dengan kriteria pengujian yaitu jika $t_{\text {hitung }}>\mathrm{t}_{\text {tabel }}$ maka Ho ditolak dan Ha diterima atau Jika $t_{\text {hitung }}<t_{\text {tabel }}$, maka Ho diterima dan Ha ditolak pada taraf signifikansi 5\%.Hasil uji-t dari posttest pemahaman konsep IPA dapat dilihat $t_{\text {hitung }}>t_{\text {tabel }}$ yaitu $9,262>2,035$ pada taraf signifikan $5 \%$ dengan derajat kebebasan (df) $=17+18-2=33$ Sesuai dengan kriteria pengujian hipotesis yaitu $t_{\text {hitung }}>t_{\text {tabel }}$, maka Ha diterima dan Ho ditolak. Hal ini menunjukkan bahwa ada pengaruh yang signifikan penggunaan model pembelajaran inkuiri terhadap pemahaman konsep IPA siswa kelas V di SDN Peresak Bebuak tahun ajaran 2020/2021.

\section{Saran}

Berdasarkan pada hasil dan kesimpulan yang telah diuraikan di atas, maka diharapkan untuk: (1) Bagi Kepala Sekolah diharapkan dapat mendukung agar proses pembelajaran berjalan dengan baik dan maksimal, salah satunya dengan memperhitungkan model pembelajaran inkuiri untuk diterapkan dalam pelajaran IPA agar siswa mampu untuk mengoptimalkan pemahaman konsep IPA siswa guna memperbaiki kualitas pendidikan; (2) Bagi guru, dapat digunakan sebagai salah satu acuan pilihan metode pembelajaran dalam mengajar IPA agar dapat mempengaruhi kualitas kegiatan belajar mengajar khususnya pada materi pembelajaran IPA sehingga pemahaman konsep IPA dapat berkembang. \& (3) Bagi siswa, dapat digunakan sebagai salah satu pilihan proses belajar agar lebih menyukai mata pelajaran IPA sehingga dapat menyelesaikan soal-soal yang diberikan sesuai dengan kemampuan yang dimilikinya. 


\section{DAFTAR PUSTAKA}

Akbar, Aulia. 2017. Membudayakan Literasi dengan Program 6M di Sekolah Dasar. JPSD. Vol. 3. No. 1, Maret 2017

Handayani, B. S, dkk. 2020. Sosialisasi Pembelajaran Berbasis Kerja Otak dan Implikasinya dalam Pembelajaran di SD Kabupaten Lombok Timur. Jurnal Pengabdian Masyarakat Sains Indonesia (JPMS). 2(1):78-83.

Khair, B. N., dkk. 2018. Pengembangan Bahan Ajar IPA Berbasis Inkuiri Untuk Siswa Kelas V SD. Elementary School Education Journal (ELSE). Vol. 2 No. 1 Februari 2018. Kristanto, Y. E. dan Susilo, H. 2015. Pengaruh Model Pembelajaran Inkuiri Terbimbing Terhadap Kemampuan Berpikir Kritis dan Hasil Belajar IPA Siswa Kelas VII SMP. JURNAL PENDIDIKAN DAN PEMBELAJARAN. Vol. 22. No. 2, Oktober 2015

Rofiqoh. 2016. Pengaruh Pendekatan Inkuiri Terhadap Hasil Belajar Peserta Didik Dalam Mata Pelajaran IPA Kelas IV SD Negeri Mannuruki. Skripsi. UIN Alauddin Makasar.

Sochibin, B, dkk. 2009. Penerapan Model Pembelajaran Inkuiri Terpimpin Untuk Peningkatan Pemahaman dan Keterampilan Berpikir Kritis Siswa SD. Jurnal Pendidikan Fisika Indonesia. Vol. 5 No. Juli 2009. 96-101

Sugiyono. 2018. Metode Penelitian kuantitatif, kualitatif,dan R\&D. Bandung: Alfabeta. 